\title{
Tarım Sigortaları Kapsamında Tarım Üreticilerinin Yenilikçilik Tutumları
}

DOI: $10.26466 /$ opus. 907938

$*$

\author{
Ali Kahramanoğlü \\ * Dr.Öğr. Üyesi Ondokuz Mayıs Üniversitesi Bafra İşletme Fakültesi, Samsun, Türkiye \\ E-Posta: ali.kahramanoglu@omu.edu.tr \\ ORCID: $\underline{0000-0002-8333-9151}$
}

\begin{abstract}
Öz
Bu araştırmada; Tarım üreticilerinin özellikle 'Tarım Sigortaları' kapsamında yenilik beklentileri ve tutumları araştııılmıştır. Tarım sigortasının bilinirliğinin artırılması ve kullanımının yaygıılaşması ile üreticilerin sektörel yeniliklerden haberdar olması arasındaki ilişki ortaya koyulmuştur. Araştırma kapsamında Samsun İli merkez ilçelerinde 2019 yılında Çiftçi Kayıt Sistemine kayıtl 1.471 tarım üreticisinden, oransal örnekleme yöntemi ile hesaplanmış 168 Tarımsal üreticisine açık uçlu sorular ve yüz yüze mülakatlar ile cevaplar alınmış ve sınıflandırılmıştır. Elde edilen bulgular ile sigorta yaptıran ve yaptırmayan işletmelerin yeniliklere bakışı, yenilikçiliğe ulaşmasında aracılar ve engeller ile yenilikçiliğe karşı tutumları hakkındaki sonuçlara ulaşılmışıı. Tarım sigortalarının çıkış nedenlerinden biri olan üreticileri ulaşmak ve yeniliklerin aktarılmasını sağlama amacına ulaşılmadığı görülmektedir. Yenilikçilik faaliyetlerinin üreticilere ulaştırılması konusunda ciddi eksiklikler bulunmaktadır. Özellikle kamu kuruluşlarının yenilik faaliyetlerinde üreticilerle iletişiminin artırılması ve bilgi vermesi amacıyla programlar düzenlemesi sağlanmalıdır. Yenilik faaliyetlerinin mali yük getirmesi nedeniyle pilot bölgeler seçilmeli ve proje desteği yoluyla planlı destekler sağlanmalıdır. Ayrıca yenilikleri uygulayan işletmelere maddi destek verilmesi bu çalışmaların yaygınlaşmasını destekleyecektir. Araştırma tarım sigortası ile yenilik aktarımı konusunda tarım işletmelerinin durumunun görülmesini să̆layan özgün bir araştırmadır.
\end{abstract}

Anahtar Kelimeler: Sigorta, Yenilikçilik, Tarım Sigortası, Yenilikçilik Kanalları, Yenilikçilik Engelleri 


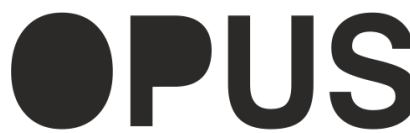

Uluslararası Toplum Araştırmaları Dergisi International Journal of Society Researches
E-ISSN : 2528-9535

Yıl Year: 11

Cilt Volume: 18

Sayı Issue :Yönetim ve Organizasyon Özel Sayısı

Temmuz July 2021

Makalenin Geliş Tarihi Received Date: 01/04/2021

Makalenin Kabul Tarihi Accepted Date: 03/06/2021

\title{
Innovative Attitudes of Agricultural Producers within Agricultural Insurances
}

\begin{abstract}
In this study; Innovation expectations and attitudes of agricultural producers, especially within the scope of "Agricultural Insurance", have been researched. The relationship between increasing the awareness of agricultural insurance and its widespread use and understanding of the producers about sectoral innovations has been revealed. Within the scope of the research, calculated with proportional sampling method, 168 agricultural producers' answers were received and classified by open-ended questions, and face-to-face interviews from 1.471 agricultural producers registered in the Farmer Registration System in the central districts of Samsun in 2019. With the findings obtained, the results have been reached with the perspective of the enterprises that have insurance and those who do not, the intermediaries and obstacles in getting innovation and their attitudes towards innovation. It is seen that one of the reason for the existence of agricultural insurance has not been achieved, which is the aim of reaching the producers and ensuring the transfer of innovations. There are severe deficiencies in delivering innovation activities to producers. Programs should be organized to increase the communication between public institutions and producers in innovation activities and provide information. Pilot regions should be selected and planned support should be provided through project support since innovation activities bring financial burden. Besides, providing financial support to enterprises implementing innovations will support the spread of these studies. The research is original research that enables the situation of agricultural enterprises to be seen on agricultural insurance and innovation transfer.
\end{abstract}

Key Words: Insurance, Innovation, Agricultural Insurance, Innovation Channels, Innovation Barriers. 


\section{Giriş}

Dünyanın hızlı bir şekilde değişmesi ve gelişmesiyle, işletmelerin rekabet koşulları gün geçtikçe zorlaşmaktadır. Pazardaki aktörlerin her geçen gün artması, kaynakların kıtlaşması, teknolojinin hızla gelişmesi, arzın artması, rakip ürünlerin fiyatlarının birbirine yaklaşması sonucu olarak işletmeler pek çok değişikliğe ayak uydurmak durumundadır. Rakiplerinden farklı bir konumda olmak isteyen işletmeler ise değişimin öncüsü olmak zorundadır. Günümüzün çetin rekabet koşullarında, işletmelerin ayakta kalabilmesini ve sürdürülebilir rekabet üstünlüğü elde edebilmesini sağlayacak en önemli anahtar, yenilikçilik yeteneğine sahip olmaktır. $\mathrm{Bu}$ yüzden işletmeler yenilikçi olmaya son derece önem vermektedir.

Yenilik kavramı yöntem olarak; fikirleri pazarlanabilir ürün veya hizmete dönüştürmektir. Bu yöntemler bazen daha önce var olmamış ürünler, hizmetler ve yönetim stratejiler olduğu gibi, başka alanlarda daha önce kullanılmış yöntemlerin farklı alanlarda kullanılması da olabilir(Van Aduard ve Macedo-Soares, 2016, s.6). Modern zamanlarda yenilikçilik yöntemlerin kullanılması hem devletlerde hem de özel sektörde zorunluluk halini almaktadır. Bu sebepler gelişen ve küreselleşen pazarlardan daha yüksek pay almak için, tüm işletmeler yönetim planlarının parçası olarak araştırma geliştirme faaliyetlerinin yanında stratejik ortaklıklara yönelmesini sağlamaktadır (Karakayacı ve Dinçer, 2018, s.381).

Tarım sektörünün modern duruma uyum sağlaması için inovasyon ve sigorta iki önemli seçenektir (Kunreuther, 2015, s.747). Rekabetçi, sürdürülebilir, üretken ve dayanıklı tarım işletmeleri desteklemek için politikalar geliştirmek Ekonomik Kalkınma ve İşbirliği Örgütü (OECD) ve Dünyanın en büyük ekonomileri arasında yer alan 19 ülkeden ve Avrupa Birliği Komisyonu'ndan oluşan (G20) hükümetleri için yüksek bir önceliktir (OECD, 2016, s.12). OECD ve bağlı kurumlar; tarım alanında yenilik, verimlilik ve sürdürülebilirlik için hükümetlere politika ve teşvik alanları bağlamında adımlar atılarak, yenilik faaliyetlerinin verimli ve sürdürülebilir olması yönünde danışmanlık hizmetleri vermektedir. $\mathrm{Bu}$ faaliyetlerin gelişip geniş işletme kitlelerine ulaşması amacıyla ferdi ve organizasyonel çalışmaların birbirlerini etkilemesinden ortaya çıkan iletişim ve paylaşım ağlarının kurulması, sistematik yenilikçilik süreçleri olarak kullanılmaktadır (Demiryürek ve Aydoğan, 2010, s.4). Yenilikçilik 
ağları sayesinde yenilikçi ürünler, hizmetler ve süreçlerin verimliliğinin artması ve maliyetlerin azaltılması için yeni organizasyon sistemleri ile işletme yönetim şekillerinin ve faaliyet iş akış süreçlerinin daha geniş kitlelere yayılması sağlanabilecektir (World Bank, 2006, s.9).

Türkiye' de tarımsal yenilik uygulanma aşamalarından en önemlisi tarım sigortaları olarak ortaya çıkmıştır. Bu yapı sayesinde devletten prim desteği alabilmek için üreticiler çiftçi kayıt sistemine üye olmaktadır. Desteği almak isteyenlerin kayıtlanmasıyla ürünler kayıt altına alınmakta birlikte üretimler de kayıt altına alınmaktadır. Bu sayede üreticilere yenilikler hakkında bilgi verecek iletişim kanalı oluşturulmakta ve üretim kontrolü sağlanmaktadır.

$\mathrm{Bu}$ çalışmada; tarım üreticilerinin tarım sigortaları bağlamında yeniliklere bakışı, yenilikçiliğe ulaşmasında aracılar ve engeller ile yenilikçiliğe karşı tutumları; açı uçlu sorular ve yüz yüze mülakatlarla araştırilmıştır.

\section{Literatür İncelemesi}

Schumpeter (1961)'e göre yenilik, beş olayı kapsamaktadır. Bunlar:

-Tüketicilerin henüz alışık olmadığı türde veya ürün kalitesinin geliştirilmesiyle oluşturulan yeni ürünlerin piyasaya sunumu,

-İlgili alanda daha önce hiç denenmemiş, bilimsel olarak yeni bir keşif üzerine kurulu ancak hangi ihtiyaca yönelik olduğu henüz bilinmeyen yeni bir üretim yöntemi veya mevcut olan bir ürünün yeni bir ticari yöntemle ele alınması,

-Yeni bir pazarın açılması; hammaddeler veya yarı mamullerin tedarik edilmesinde yeni kaynakların kazanılması,

-Herhangi bir endüstride yeniden örgütlenme faaliyetleridir.

OECD ve Eurostat'in ortak olarak yayımladığı Oslo Kılavuzu'nun 3. baskısına göre yenilik; 'işletme içi uygulamalarda, işyeri organizasyonunda veya dış ilişkilerde yeni veya önemli derecede iyileştirilmiş bir ürün (mal veya hizmet) veya süreç, yeni bir pazarlama yöntemi ya da yeni bir örgütsel yöntemin gerçekleştirilmesidir.'

Bu tanımlardan yola çıkılarak tarım sigortası bağlamında üretim işletmelerinin yenilikçilik ile ilişkilendirildiği konularda yapılmış çalışmalar taranmıştır. 
İpekçioğlu vd. (2010) çalışmasında; Şanlıurfa, Diyarbakır ve Adıyaman illerinde yaptıkları araştırmada, tarım sigortası yaptıran üreticilerin $\% 62$ 'sinin, yaptırmayan üreticilerin ise \%48.00'inin çevrelerinde yenilikleri benimseyip uygulayan ilk kişi olarak tespit etmişlerdir.

Yavuz ve Tatlıdil (2011) çalışmalarında; Polatlı ilçesinde 157 üretim işletmesinde araştırma yapmıştır. Katılımcıların \%70,70'inin hem tarım sigortaları hem de yenilikler hakkında kurumsal olmayan kaynaklar kanalıyla bilgiye ulaştıkları saptanmıştır. Bu durum, Tarım sigortası yaptıran ve yaptırmayan tüm üreticiler için farklılık göstermemektedir. Bunun yanında, tarım sigortası yaptıranların tarım sigortası konusunda kurumsal olmayan bilgi kaynaklarının kullanımı \%66,20 iken bu oran tarım sigortası yaptırmayanlarda ise \%74,42'ye yükseldiğini saptamışlardır.

Tümer (2011) çalışmasında; üreticilerden 56'sının, sigorta yaptırmadığını ortaya koymuştur. Afiş, radyo ve televizyon, broşür, sirküler mektup gibi kitle yayım araçları kullanılarak çiftçilerin yenilikler hakkında bilinçlendirilmesinin sağlanacağını ortaya koymuştur. Tarım sigortası yaptıran ve yaptırmayan üreticiler yenilikleri en çok kamu kurumlarından, yakın çevrelerinden ve medyadan öğrenmişlerdir. Sigorta yaptıran ve yaptırmayan üreticilerin büyük çoğunluğunun eğitim, toplantı vb. bir etkinliğe katılmadığı belirlenmiştir. Tarımsal yenilikler açısından incelendiğinde ankete katılanların \%10,40'i tamamen uygulamakta, \%41,97'si çoğunlukla uygulamakta ve $\% 14,81$ 'i ise ara sıra uygulamaktadır. Tarım sigortası yaptıran işletmeler incelendiğinde ankete katılanların yarısı hemen uygulamakta, tarım sigortası yaptırmayan işletmelerde \%20'si tamamen uygulamaktadır. İncelenen işletmeler incelendiğinde; tarımsal yenilikleri \%79,01 oranında yayım elemanlarından öğrendikleri görülmektedir. Görsel ve yazılı basın ve önder çiftçilerin de önemli oranda etkili olduğu görülmektedir. Tarım sigortası yaptıran işletmelerde ankete katılan kişilerin \%58,92'si yenilikleri hemen kabul ederken, tarım sigortası yaptırmayan işletmelerde $\% 72,00$ 'sinin ise yenilikleri diğer üreticiler kabul ettikten sonra kabul ettikleri görülmektedir.

Pezikoğlu (2012) Bursa ilinde yaptığı araştırmada; sigorta yaptıran üreticilerin \%53.6'sının yenilikleri uyguladığını sonucuna ulaşmıştır. Bunların; \%17.9'unun hemen, \%14.3'ünün yenilikleri tümüyle başarılı olduktan sonra ve \%14.3'ünün önce deneyip sonra uyguladığını sapta- 
mıştır. Sigorta yaptırmayan üreticilerin ise \%48.0'inin yenilikleri tümüyle başarılı olduktan sonra, \%40.0'inın yenilikleri uygulayanların sonucuna baktıktan sonra, \%8.0'inin hemen ve \%4.0'ünün önce deneyip sonra uyguladıklarını saptamıştır. Sonuç olarak; sigorta yaptıran üreticilerin, sigorta yaptırmayan üreticilere göre daha yenilikçi olduklarını tespit etmiştir.

Alay (2012) Kastamonu ilinde yaptığı çalışmada, üreticilerin genellikle tarımsal yenilikleri, tarım sigortas1 yaptıran üreticilerin \%58.92'sinin hemen kabul ettiğini, tarım sigortası yaptırmayan üreticilerin \%72.00'sinin diğer üreticilerden sonra kabul ettiklerini saptamıştır.

Sungur vd. (2014) çalışmalarında; tarım sektöründe faaliyet gösteren firmaların yenilikçilik faaliyetlerinde kamu kurumlarıya işbirliği düzeyinin çok düşük olduğunu ortaya koymaktadır. Bunun dişında genel olarak bakıldığında; firmaların yenilikçilik sürecinde kurumsal yapılarla işbirliği düzeyinin de aynı seviyede düşük olduğu saptanmıştır.

Karamürsel vd. (2014) Isparta ilinde yaptıkları araştırmada; sigorta yaptıran üreticilerin yeniliklerin \%42.11'inini kamu kurumlarından, \%35.09'unun önder çiftçilerden, sigorta yaptırmayan üreticilerin ise \%45.90'ının kamu kurumlarından, \%40.98'inin önder çiftçiler sayesinde ulaştıkları sonucuna ulaşmıştır. Üreticilerin \%45.31'i yenilikleri ucuzluğundan, \%37.24'ü yenilikler hakkında bilgili olduğundan dolayı benimsediklerini sonucuna ulaşmıştır. Üreticilerin \%47.66'sı yenilikleri maddi problemlerden, \%41.14'ü sadece bilgiye ulaşamamaktan dolayı yeniliklerden uzak oldukları sonuçlarına ulaşmıştır.

Yazg1 ve Olhan (2018) çalışmalarında; Tekirdağ ilinde 192 üretim işletmesi üzerinde yaptığı çalışmada; üreticilerin tamamına yakınının yenilik programları konusunda bilgi sahibi olmadığını ortaya koymuştur.

İşbeceren (2018) 65 üreticiyle yaptığı çalışmasında; üreticilerin 46 'sının tarım sigortası yaptırdığını ve 19'unun yaptırmadığını, bunun yanında tarım sigortası yaptıranların \%87'sinin kredi kullanırken tarım sigortası yaptırmayan üreticilerin ise kredi kullanma oranı $\% 58$ olduğunu ortaya koymuştur. Katılımcıların \%38'inin kamu kurumları kanalıyla bilgi sahibi olduğu ve \%27' sinin yenilik eğitimi aldığı sonuçlarına ulaşmiştır.

Nalinci (2018) 384 üretici ile yaptığı çalışmasında; üreticilerin yenilikleri Kabul etme düzeylerinin \%47.66'sı diğer üreticilerden sonra, \%30.01'i 
herkesten sonra ve \%9.76'sı hemen kabul ettiğini ortaya koymuştur. Üreticilerin tarımsal yeniliklerin \%33.33'ü çoğunluğunu, \%31.77'si çok azını, \%24.74'ü bazılarını uyguladığını ortaya koymuştur. Yenilikler bağlamında üreticilerin \%49.22'si önder çiftçilerden, \%25.52'si yayım elemanlarından dolayı haberdar oldukları belirtilmiştir.

Kabaoğlu ve Birinci (2019) çalışmasında; 319 üreticiyle yüz yüze görüşmeler yapmış ve \%62,35'inin tarım sigortası yaptırmadı̆̆ını ortaya koymuştur.

\section{Yöntem}

2019 yılında Türkiye'nin milli geliri yaklaşık 5 trilyon TL'ye ulaşmış olup, bunun \%6,4'ünü (yaklaşık 340 milyar Türk Lirası) tarım sektörü oluşturmuştur. Aynı yıl tarım sigortaları açısından incelendiğinde; 2.087.860 adet Poliçe oluşturulduğu, Sigorta bedelinin 55.166.348.492 TL, prim üretiminin 2.447.064.788 TL ve ödenen hasarın 1.226.860.024 TL olduğu görülmektedir (TARSIM Faaliyet Raporu, 2019). Üretim hacmi ve parasal karşıllı̆ının yanında istihdama katkısı açısından da makroekonomi için desteklenen en önemli sektörlerden birinin üyesi olan tarım üreticilerine açık uçlu sorular ile veri seti elde edilmiştir.

Araştırmanın örnek hacmi, oransal örnekleme yöntemi ile belirlenmiştir (Newbold, 1995).

$$
\mathrm{n}=\frac{\mathrm{Np}(1-\mathrm{p})}{(\mathrm{N}-1) \sigma^{2} \mathrm{px}+\mathrm{p}(1-\mathrm{p})}
$$

$\mathrm{N}$ : Samsun merkez ilçelerinde Çiftçi kayıt sistemine kayıtlı üretici sayısı (Araştırma Evreni),

n: Örneklem büyüklüğü

p: Evrendeki kredi kullanan üreticinin gözlenme oranı, (maksimum örnek hacmine ulaşmak için 0,50 alınmıştır)

$\sigma^{2} \mathrm{px}=$ Varyans1 vermektedir.

Araştırma kapsamında örneklemin, Samsun İli merkez ilçelerinde (Atakum, İlkadım, Canik ilçeleri) 2019 yılında Çiftçi Kayıt Sistemine kayıtlı 1.471 tarım üreticisinden \%90 güven aralığında ve \%6 hata ile örnek hacminin 167 olması gerektiği bulunmuştur. Ziraat Odalarından elde edilen veriler yardımıyla görüşülen tüm üreticilerin içinden 168 üretici 
ile yüz yüze mülakat yapılmıştır ve açık uçlu soruların cevaplarını sınıflandırarak veri seti elde edilmiştir.

Yüz yüze görüşmelerde; Alay (2012), Karamürsel vd. (2014), İşbeceren (2018) ve Nalinci (2018) çalışmalarında kullanılan anket soruları değerlendirilerek soru formu oluşturulmuştur. Soru formunda işletmelerin sahiplerine demografik ve temel bilgileri içeren 7 temel soruya öncelikle cevap aranmıştır. Bunlar; Cinsiyet, Yaş Grubu, Medeni Durum, İş Deneyimi, Eğitim Durumu, Yenilik Eğitimi Alma, Kredi Kullanımı ve Tarım Sigortası yaptırmaları olarak değerlendirilmiştir. Bunun yanında diğer bölümlerde; Yeniliklere karşı tutum, Yenilikleri uygulama oranları, Yenilikleri öğrenme kaynakları, Yeniliği benimsemesini teşvik eden etmenler ve herhangi bir yeniliğin uygulamasında yaşanan sıkıntılar araştırılmış ve analiz edilmiştir. Soruların cevapları alınırken literatürde oluşan örnek cevapların dışında da cevap verilebilmesi için yöneticilere sorular açık uçlu sorulmuştur. Sonuçlar analiz edilirken işletmeler 'Sigorta Yaptıranlar' ve 'Sigorta Yaptırmayanlar' olarak hem ayrı ayrı hem de birlikte değerlendirilmiştir.

Bu araştırmada; Tarım üreticilerinin özellikle 'Tarım Sigortaları' kapsamında yenilik beklentileri ortaya koyulmuş ve bu sigortanın bilinirliğinin artırılması ve kullanımının yaygınlaşması için reel sektörde faaliyet gösteren işletmelerin durumu ortaya koyulmuştur.

\section{Bulgular}

Çalışmada; tarım üreticilerinden alınan açık uçlu da olan sorulara verilen cevaplar sınıflandırılmış ve nihai bulgulara ulaşılmıştır. 168 katılımcının \%92,26'sının erkeklerden \%7,74'ünün ise kadınlardan oluştuğu görülmektedir. Yaş grubu olarak \%4,17'sinin 30 yaş altı, 22,62'sının 30-40 yaş arası, \%38,69'unun 40-50 yaş arası, \%25,00'inin 50-60 yaş arası ve $\% 9,52$ 'sinin 60 yaş ve üstü olduğu görülmektedir. Üreticilerin \%19,05'inin bekar buna karşın \%80,95'inin ise evli olduğu görülmektedir. İş tecrübeleri açısından incelendiğinde; \%7,14' ünün 5 yıldan az, $\% 20,24$ 'ünün 5-10 yıl arası, \%35,12' sinin 10-20 y1l arası, \%30,95' inin 20-30 yıl arası ve $\% 6,55$ 'inin ise 30 yıl ve üzeri iş deneyimine sahip olduğu görülmektedir. Katılımcıların \%37,50'sinin İlköğretim, \%28,57'sinin Lise, \%13,10'unun Ön lisans, \%19,64'ünün Lisans ve \%1,19'unun Lisansüstü 
eğitim aldıkları görülmektedir. Üreticilerin \%23,21' sinin yenilikçilik eğitimi aldıkları \%76,79'unun ise almadığ 1 görülmektedir. Üreticilerin \%83,93'ü Kredi kullanırken \%16,07'si kullanmamaktadır. Katılım sağlayanların \%61,90'unun tarım sigortası yaptırdığı buna karşın \%38,10'unun yaptırmadığı görülmektedir. Katılımcıların demografik özelliklerinin yanında yenilik eğitimi alma, kredi kullanma ve tarım sigortası yaptırma durumları Tablo 1'de verilmiştir.

Tablo 1: Araştırmaya Katılan Tartm Üreticilerinin Demografik Özelliklerine İlişkin Bilgiler

\begin{tabular}{llll}
\hline $\begin{array}{l}\text { Demografik Özellikler } \\
\text { N(Katılımcı Sayısı)(168) }\end{array}$ & & F (Frekans) & \% (Oran) \\
\hline \multirow{2}{*}{ Cinsiyet } & Bayan & 13 & $7,74 \%$ \\
& Bay & 155 & $92,26 \%$ \\
\hline \multirow{3}{*}{ Yaş Gurubu } & 30 altı & 7 & $4,17 \%$ \\
& $30-40$ arası & 38 & $22,62 \%$ \\
& $40-50$ arası & 65 & $38,69 \%$ \\
& $50-60$ arası & 42 & $25,00 \%$ \\
\multirow{2}{*}{ Medeni Durum } & 60 ve üstü & 16 & $9,52 \%$ \\
\hline \multirow{2}{*}{ Yenilik Eğitimi Alma } & Bekâr & 32 & $19,05 \%$ \\
& Evli & 136 & $80,95 \%$ \\
\hline \multirow{4}{*}{ İş Deneyimi } & Evet & 39 & $23,21 \%$ \\
& Hayır & 129 & $76,79 \%$ \\
\hline \multirow{2}{*}{ Eğitim Durumu } & 5 yılldan az & 12 & $7,14 \%$ \\
& $5-10$ yll & 34 & $20,24 \%$ \\
& $10-20$ yıl & 59 & $35,12 \%$ \\
& $20-30$ & 52 & $30,95 \%$ \\
\multirow{2}{*}{ Kredi Kullanımı } & 30 ve üzeri & 11 & $6,55 \%$ \\
\hline & İlköğretim & 63 & $37,50 \%$ \\
& Lise & 48 & $28,57 \%$ \\
& Ön lisans & 22 & $13,10 \%$ \\
& Lisans & 33 & $19,64 \%$ \\
& Lisansüstü & 2 & $1,19 \%$ \\
\hline & Evet & 141 & $83,93 \%$ \\
& Hayır & 27 & $16,07 \%$ \\
\hline
\end{tabular}

Üreticilerin cevapları incelendiğinde; tarım sigortası yaptıranların $\% 18,27$ 'sinin yenilikleri hemen kabul ettiği, \%50,96'sının diğer işletmelerden sonra kabul ettiği ve \%30,77'sinin herkesten sonra kabul ettiği görülmektedir. Tarım sigortası yaptırmayanların \%18,75'inin yenilikleri hemen kabul ettiği, \%28,13'ünün diğer işletmelerden sonra kabul ettiği 
ve \%53,13'ünün herkesten sonra kabul ettiği görülmektedir. Tüm kat1lımcılar incelendiğinde \%18,45'inin yenilikleri hemen kabul ettiği, $\% 42,26$ 'sının diğer işletmelerden sonra kabul ettiği ve \%39,29'unun herkesten sonra kabul ettiği görülmektedir. Tarım Üreticilerinin yeniliklere karşı tutumları ilişkin cevapların sınıflandırılması Tablo 2' de verilmiştir.

Tablo 2: Tarım Üreticilerinin Yeniliklere Karşı Tutumları

\begin{tabular}{lllcllll}
\hline \multirow{2}{*}{ Yeniliklere Karşı Tutumları } & \multicolumn{2}{c}{ Tarım Sigortası } & \multicolumn{2}{c}{ Yaptıran } & \multicolumn{2}{c}{ Yaptırmayan } & \multicolumn{2}{c}{ Toplam } \\
& f & $\%$ & f & $\%$ & f & $\%$ \\
\hline Hemen kabul eder & 19 & $18,27 \%$ & 12 & $18,75 \%$ & 31 & $18,45 \%$ \\
Diğer üreticilerden sonra kabul & 53 & $50,96 \%$ & 18 & $28,13 \%$ & 71 & $42,26 \%$ \\
eder & & 32 & $30,77 \%$ & 34 & $53,13 \%$ & 66 & $39,29 \%$ \\
Herkesten sonra kabul eder & 104 & $100,00 \%$ & 64 & $100,00 \%$ & 168 & $100,00 \%$ \\
Toplam & & & & & &
\end{tabular}

Tarım sigortası yaptıranların \%17,31'inin yeniliklerin tamaminı, \%33,65'inin çoğunluğunu, \%30,77'inin bazılarını ve \%18,27'sinin çok azını uyguladığı görülmektedir. Tarım sigortası yaptıranlar işletmelerden yenilikleri hiç kullanmayan olmadığı görülmektedir. Tarım sigortası yaptırmayanların \%10,94'ünün yeniliklerin tamamını, \%18,75'inin çoğunluğunu, \%29,69'unun bazılarını, \%26,56'sının çok azını uyguladı̆̆ 1 ve \%14,06'sının hiçbir yeniliği uygulamadığı görülmektedir. Tüm katılımc1lar incelendiğinde; işletmelerin \%14,88'i yeniliklerin tamamını, 27,98'i çoğunluğunu, \%30,36'sının bazılarını, \%21,43'ünün çok azını uyguladığ ve $\% 5,36$ 'sının ise hiçbir yeniliği uygulamadığı görülmektedir. Tarım Üreticilerinin yenilikleri uygulamasına ilişkin cevapların sınıflandırılması Tablo 3'de verilmiştir.

Tarım sigortası yaptıranların \%14,42'sinin yenilikleri yayım elemanlarindan, \%47,12'sinin lider firmalardan, \%7,69'unun görsel basindan, $\% 4,81$ 'inin yazllı basından, \%8,65'inin internet kaynaklarından, \%13,46'sının kamu kuruluşlarından ve \%3,85'inin çiftçilerden öğrendiği görülmektedir. Tarım sigortası yaptırmayanların ise \%17,19'unun yenilikleri yayım elemanlarından, \%56,25'inin lider firmalardan, \%4,69'unun görsel basından, \%3,13'ünün yazılı basından, \%7,81'inin internet kaynaklarından, \%9,38'nin kamu kuruluşlarından ve \%1,56'sının çiftçilerden öğrendiği görülmektedir. 
Tablo 3: Tarm Üreticilerinin Yenilikleri Uygulaması

\begin{tabular}{lllllll}
\hline \multirow{2}{*}{$\begin{array}{l}\text { Yenilikleri Uygulama } \\
\text { Düzeyi }\end{array}$} & \multicolumn{3}{c}{ Tarım Sigortası } & \multicolumn{2}{c}{ Yaptırmayan } & \multicolumn{2}{c}{ Toplam } \\
& f & $\mathbf{\%}$ & $\mathbf{f}$ & $\mathbf{\%}$ & $\mathbf{f}$ & $\mathbf{\%}$ \\
\hline Tamamını & 18 & $17,31 \%$ & 7 & $10,94 \%$ & 25 & $14,88 \%$ \\
Çoğunluğunu & 35 & $33,65 \%$ & 12 & $18,75 \%$ & 47 & $27,98 \%$ \\
Bazılarını & 32 & $30,77 \%$ & 19 & $29,69 \%$ & 51 & $30,36 \%$ \\
Çok azını & 19 & $18,27 \%$ & 17 & $26,56 \%$ & 36 & $21,43 \%$ \\
Hiç birini & 0 & $0,00 \%$ & 9 & $14,06 \%$ & 9 & $5,36 \%$ \\
Toplam & 104 & $100,00 \%$ & 64 & $100,00 \%$ & 168 & $100,00 \%$ \\
\hline
\end{tabular}

Tüm katılımcllar incelendiğinde $\% 15,48$ inin yenilikleri yayım elemanlarından, \%50,60'ının lider firmalardan, \%6,55'inin görsel basından, $\% 4,17$ 'sinin yazılı basından, \%8,33'ünün internet kaynaklarından, $\% 11,90$ 'ının kamu kuruluşlarından ve \%2,98'inin çiftçilerden öğrendiği görülmektedir. Tarım Üreticilerinin yenilikleri öğrenme kaynağına ilişkin cevapların sınıflandırılması Tablo 4'de verilmiştir.

Tablo 4: Tarım Üreticilerinin Yenilikleri Öğrenme Kaynă̆ı

\begin{tabular}{|c|c|c|c|c|c|c|}
\hline \multirow{3}{*}{ Yenilikleri Öğrenme Kaynağı } & \multicolumn{6}{|c|}{ Tarım Sigortası } \\
\hline & \multicolumn{2}{|c|}{ Yaptıran } & \multicolumn{2}{|c|}{ Yaptirmayan } & \multicolumn{2}{|c|}{ Toplam } \\
\hline & f & $\%$ & $\mathrm{f}$ & $\%$ & $\mathbf{f}$ & $\%$ \\
\hline Yayım elemanları & 15 & $14,42 \%$ & 11 & $17,19 \%$ & 26 & $15,48 \%$ \\
\hline Lider Firmalar & 49 & $47,12 \%$ & 36 & $56,25 \%$ & 85 & $50,60 \%$ \\
\hline Görsel basın & 8 & $7,69 \%$ & 3 & $4,69 \%$ & 11 & $6,55 \%$ \\
\hline Yazılı basın & 5 & $4,81 \%$ & 2 & $3,13 \%$ & 7 & $4,17 \%$ \\
\hline İnternet & 9 & $8,65 \%$ & 5 & $7,81 \%$ & 14 & $8,33 \%$ \\
\hline Kamu Kuruluşları & 14 & $13,46 \%$ & 6 & $9,38 \%$ & 20 & $11,90 \%$ \\
\hline Çiftçiler & 4 & $3,85 \%$ & 1 & $1,56 \%$ & 5 & $2,98 \%$ \\
\hline Toplam & 104 & $100,00 \%$ & 64 & $100,00 \%$ & 168 & $100,00 \%$ \\
\hline
\end{tabular}

Bir yeniliğin benimsemesini teşvik etmesi bakımından, tarım sigortası yaptıranların \%58,65'inde ucuz olmasının, \%30,77'sinde bilgi seviyelerinin, $\% 9,62$ 'sinde denenebilir olması ve $\% 0,96$ 'sinda basit veya kolay olmasının etkili olduğunu görülmektedir. Tarım sigortası yaptırmayanlarda ise \%35,94'ünde ucuz olmasının, \%48,44'ünde bilgi seviyelerinin, $\% 12,50$ 'sinde denenebilir olması ve \%3,13'ünde basit veya kolay olmasinın etkili olduğunu görülmektedir. Tüm katılımclar incelendiğinde ise $\% 50,00$ 'sinde ucuz olmasinın, \%37,50'sinde bilgi seviyelerinin, $\% 10,71$ 'inde denenebilir olması ve $\% 1,79$ 'unde basit veya kolay olmasinın etkili olduğunu görülmektedir. Tarım Üreticilerinin herhangi bir 
yeniliği benimsemesini teşvik eden etmenlere ilişkin cevapların sınıflandırılması Tablo 5'de verilmiştir.

Tablo 5: Tarım Üreticilerinin Herhangi Bir Yeniliği Benimsemesini Teşvik Eden Etmenler

\begin{tabular}{|c|c|c|c|c|c|c|}
\hline \multirow{3}{*}{$\begin{array}{l}\text { Teşvik Eden Etmen- } \\
\text { ler }\end{array}$} & \multicolumn{6}{|c|}{ Tarım Sigortası } \\
\hline & \multicolumn{2}{|c|}{ Yaptiran } & \multicolumn{2}{|c|}{ Yaptırmayan } & \multicolumn{2}{|c|}{ Toplam } \\
\hline & f & $\%$ & $\mathbf{f}$ & $\%$ & $\mathbf{f}$ & $\%$ \\
\hline Ucuz olması & 61 & $58,65 \%$ & 23 & $35,94 \%$ & 84 & $50,00 \%$ \\
\hline Bilgi düzeyi & 32 & $30,77 \%$ & 31 & $48,44 \%$ & 63 & $37,50 \%$ \\
\hline Denenebilir olması & 10 & $9,62 \%$ & 8 & $12,50 \%$ & 18 & $10,71 \%$ \\
\hline Basit-kolay olması & 1 & $0,96 \%$ & 2 & $3,13 \%$ & 3 & $1,79 \%$ \\
\hline Toplam & 104 & $100,00 \%$ & 64 & $100,00 \%$ & 168 & $100,00 \%$ \\
\hline
\end{tabular}

Bir yeniliğin uygulanmasında yaşanan sorunlar bakımından, tarım sigortası yaptiranların \%45,19'u maddi problemler, \%43,27'si bilgiye ulaşamamak ve \%11,54'ü ise hem maddi problemler hem de bilgiye ulaşma sorunlarının etkili olduğunu belirtmiştir. Tarım sigortası yaptırmayanların ise \%53,13'̈̈ maddi problemler, \%35,94'ü bilgiye ulaşamamak ve \%10,94'ü ise hem maddi problemler hem de bilgiye ulaşma sorunlarının bir yeniliğin uygulanmasında yaşanan sorunlar olduğunu belirtmiştir. Tüm katılımcılar incelendiğinde $\% 48,21^{\prime}$ inin maddi problemler, \%40,48'inin bilgiye ulaşamamak ve \%11,31'inin ise hem maddi problemler hem de bilgiye ulaşma sorunları nedeniyle yenilik uygulamada sorun yaşadığı görülmektedir. Tarım Üreticilerinin herhangi bir yeniliğin uygulanmasında yaşanan sorunlar ilişkin cevapların sınıflandırılması Tablo 6'de verilmiştir.

Tablo 6: Tarım Üreticilerinin Herhangi Bir Yeniliği Uygulamasında Yaşanan Sorunlar

\begin{tabular}{|c|c|c|c|c|c|c|}
\hline \multirow{3}{*}{ Yaşanan Sıkıntılar } & \multicolumn{6}{|c|}{ Tarım Sigortası } \\
\hline & \multicolumn{2}{|c|}{ Yaptıran } & \multicolumn{2}{|c|}{ Yaptırmayan } & \multicolumn{2}{|c|}{ Toplam } \\
\hline & f & $\%$ & $\mathbf{f}$ & $\%$ & $\mathbf{f}$ & $\%$ \\
\hline Maddi problemler & 47 & $45,19 \%$ & 34 & $53,13 \%$ & 81 & $48,21 \%$ \\
\hline Bilgiye Ulaşamamak & 45 & $43,27 \%$ & 23 & $35,94 \%$ & 68 & $40,48 \%$ \\
\hline Her ikisi & 12 & $11,54 \%$ & 7 & $10,94 \%$ & 19 & $11,31 \%$ \\
\hline Toplam & 104 & $100,00 \%$ & 64 & $100,00 \%$ & 168 & $100,00 \%$ \\
\hline
\end{tabular}




\section{Tartışma ve Sonuç}

Bulgular incelendiğinde özellikle yeniliklerin üreticilere aktarılması ve üretimlerin kayıt altına alınması amacıyla tasarlanmış, tarım sigortalarının, 168 katılımcının 104' ̈̈ tarafından yaptırıldığını ve 64'ü tarafından yaptırılmadığ 1 görülmektedir. Bu durum literatür taramasında incelenen, İşbeceren (2018); Nalinci (2018); Karamürsel vd. (2014); İpekçioğlu vd. (2010); Yavuz ve Tatlıdil (2011) çalışmalarıyla uyumlu olduğu ancak Kabaoğlu ve Birinci (2019) ve Tümer (2011); çalışmalarının sonuçlarıyla uyumlu olmadığı görülmektedir. Bunun temel sebebi bölgesel farklılıklar ve geleneksel alışkanlıklar olduğu söylenebilir.

Yenilik Eğitimi Alma konusunda katılımclardan 39'u olumlu cevap verirken, 129 katılımcı yenilik eğitimi almadığını belirtmiştir. Bu sonuçlar; İşbeceren (2018); Nalinci (2018); Yazg1 ve Olhan (2018); Sungur vd. (2014) ve Tümer (2011); çalışmalarıyla örtüşmektedir. Bu sonuçlarla farklı yıllarda farklı bölgelerde yapılan çalışmaların da sonucu olarak yenilik eğitiminin üreticilere ulaşmasında büyük eksiklikler görülmektedir.

Yeniliklere Karşı Tutumları açısından sonuçlar değerlendirildiğinde; katılımcların hem sigorta yaptıranları hem de yaptırmayanlarının hemen kabullenmediği ve genelde diğer üreticileri beklediği sonucuna ulaşılmıştır. Bu sonuçlar, Pezikoğlu (2012); Nalinci (2018) ve Tümer (2011); çalışmalarıyla uyumlu olduğu ancak İpekçioğlu vd. (2010) ve Alay (2012); çalışmalarıyla uyumlu olmadığı görülmektedir.

Üreticilerin yeniliklerin uygulaması konusunda katılımcıların özellikle sigorta yaptıranlarının daha olumlu davrandığını ve yenilik çalışmalarını daha fazla uyguladığı sonucuna ulaşılmıştır. Bu sonuçlar, Nalinci (2018) çalışmasıyla uyumlu ancak Sungur vd. (2014) ve Tümer (2011); çalışmalarıyla farklılık göstermektedir. Özellikle Sungur vd. (2014) çalışmalarında yenilik uygulamalarının çok düşük seviyede olduğu sonucuna ulaşmış ve bu durumu bölgesel farklılıkla açıklamaktadır.

Yenilikleri öğrenme kaynağı olarak; katılımcıların hem sigorta yaptıranları hem de yaptırmayanlarının yayım elemanları ve lider firmaları çoğunlukla takip ettiği ama kamu kuruluşları ve internet kullanımının daha az kabul gördüğü sonucuna ulaşılmıştır. Nalinci (2018)'nın çalışmasında bulduğu yeniliklerin \%49.22'si lider firmalardan öğrenildiğini, Yavuz ve Tatlıdil (2011) de yenilikleri öğrenmek için katılımcıların 
$\% 66,20^{\prime}$ sinin kurumsal olmayan bilgi kaynaklarının kullandığı saptamıştır. Bunun yanında yenilikleri öğrenme konusunda Sungur vd. (2014) çalışmasında kamu kurumlarıyla işbirliği düzeyinin çok düşük olduğunu ve Tümer (2011) çalışmasında tarımsal yenilikleri \%79,01 oranında en fazla yayım elemanları öğrendikleri görülmektedir. Bu sonuçlar araştırmada bulunan sonuçlarla yakınlık göstermektedir. Diğer yandan ise İşbeceren (2018) çalışmasında katılımcıların \%38'inin yenilikleri kamu kurumları aracılığıyla öğrendiğini, Karamürsel vd. (2014) yılında Isparta ilinde yaptıkları araştırmada, hem tarım sigortası yaptıran hem de yaptırmayan üreticilerin yenilikleri \%42.11 oranında kamu kurumlarından, \%35.09 oranında köydeki diğer çiftçilerden öğrendiklerini tespit etmiştir.

Yeniliği teşvik eden etmenler incelendiğinde, araştırmaya katılan üreticilerin tamamına yakını ucuz olması ve bilgi düzeyinin yüksekliği sayesinde yeniliklerin teşvik edildiğini belirtmişlerdir. Karamürsel vd. (2014) çalışmasında; yenilikleri bilgi sahibi ve olduğu ucuz olduğu benimsediğini ortaya koymuştur.

Yeniliğin uygulanmasında yaşanan sıkıntılar olarak katılımcıların tamamına yakını maddi problemler veya bilgiye ulaşamamak olarak belirtmiştir. Bu sonuç Karamürsel vd. (2014) çalışmasıyla örtüşmektedir. Yenilik uygulamaların yaygınlaşması için ek teşvikler verilmeli ve iletişim kanalları güncellenmelidir.

Bulgular ve literatür taraması sonucu olarak; tarım sigortalarının çıkış nedenlerinden biri olan üreticileri ulaşmak ve yeniliklerin aktarılmasını sağlama amacına ulaşılmadığı görülmektedir. Özellikle kamu kuruluşlarının yenilik faaliyetlerinde üreticilerle iletişiminin artırılması ve bilgi vermesi amacıyla programlar düzenlemesi sağlanmalıdır. Yenilik faaliyetlerin uygulanmasının mali yük getirmesi nedeniyle pilot bölgeler seçilmeli ve proje desteği yoluyla planlı destekler sağlanmalıdır.

İlerleyen çalışmalarda özellikle tarım işletmeleri ile iletişimde olan kamu personellerinin bilgi düzeyleri araştırılabilir. Bu sayede üreticilerin yenilik bilgilerine ulaşamama ve uygulayamama nedenleri ortaya koyulabilir. 
EXTENDED ABSTRACT

\title{
Innovative Attitudes of Agricultural Producers within Agricultural Insurances \\ *
}

\author{
Ali Kahramanoğlu \\ Ondokuz Mayıs University
}

With the rapid change and development of the world, the competitive conditions of businesses are getting more complex day by day. As a result of the increasing number of actors in the market, the scarcity of resources, the rapid development of technology, the increase in supply, and the convergence of competing products, businesses have to keep up with many changes. Businesses that want to be in a different position than their competitors must be the pioneers of change. In today's harsh competitive conditions, the most critical key for businesses to survive and achieve sustainable competitive advantage is to have the ability to innovate. That is why businesses attach great importance to being innovative.

It is the method of innovation concept to transform the developed ideas into marketable products or services. These methods may sometimes be products, services, and management strategies that did not exist before and used methods previously used in other fields in different areas (Van Aduard and Macedo-Soares, 2016, p.6). In modern times, innovative methods have become a necessity both in the state and in the private sector. These reasons enable all businesses to turn to strategic partnerships and research and development activities as part of their management plans to get a higher share from developing and globalizing markets (Karakayacı ve Dinçer, 2018, p.381).

The most critical step in the implementation of agricultural innovations in Turkey has emerged as agricultural insurance. Thanks to this structure, producers become members of the farmer registration system to receive premium support from the state. With the registration of those who want to receive support, the products are recorded, and the productions are also recorded. In this way, a communication channel that will 
inform the producers about innovations is created, and production control is provided.

According to Schumpeter (1961), innovation includes five events. These:

- Launch of new products that are not yet accustomed to consumers or created by improving product quality

- A new production method, which has never been tried before in the relevant field, is based on a scientific discovery but is not yet known for what needs

- Handling an existing product with a new commercial method.

- The opening of a new market; acquisition of new resources in sourcing raw materials or semi-finished products

- Reorganization activities in any industry.

According to the 3rd edition of the Oslo Guide jointly published by the OECD and Eurostat, innovation; "It is the realization of a new or significantly improved product (good or service) or process, a new marketing method or a new organizational method in internal applications, workplace organization or external relations."

In this study; Innovation expectations and attitudes of agricultural producers, especially within the scope of "Agricultural Insurance", have been researched. The relationship between increasing the awareness of agricultural insurance and its widespread use and understanding of the producers about sectoral innovations has been revealed. Within the scope of the research, calculated with proportional sampling method, 168 agricultural producers' answers were received and classified by openended questions, and face-to-face interviews from 1.471 agricultural producers registered in the Farmer Registration System in the central districts of Samsun in 2019. With the findings obtained, the results have been reached with the perspective of the enterprises that have insurance and those who do not, the intermediaries and obstacles in getting innovation and their attitudes towards innovation.

One of the reasons for the existence of agricultural insurance has not been achieved, which is the aim of reaching the producers and ensuring the transfer of innovations. There are severe deficiencies in delivering innovation activities to producers. Programs should be organized to increase the communication between public institutions and producers in 
innovation activities and provide information. Pilot regions should be selected and planned support should be provided through project support since innovation activities bring financial burden.

Besides, providing financial support to enterprises implementing innovations will support the spread of these studies. As a result of the findings and literature review, reaching the producers and ensuring the transfer of innovations, which is one of the reasons for agricultural insurances, has not been achieved. It should be ensured that programs are organized to increase the communication between public institutions and producers in innovation activities and provide information. Since the implementation of innovation activities brings financial burden, pilot regions should be selected, and planned support should be provided through project support.

In future studies, public personnel's knowledge levels, especially those in contact with agricultural enterprises, can be investigated. In this way, the reasons for manufacturers not being able to access and implement innovation information can be revealed.

\section{Kaynakça/ References}

Alay, Ö. (2012). Kastamonu İli Tarım Kredi Kooperatiflerinde tarım sigortaları uygulamalarının değerlendirilmesi. (Y. Lisans Tezi). Gaziosmanpaşa Üniversitesi Fen Bilimleri Enstitüsü, Tokat.

Demiryürek, K. ve Aydoğan, M. (2010). Social network analysis with PAJEK. Proceedings of 3rd International Congress on Information and Communication Technologies in Agriculture, Food, Foresty and Environment

Sıray, E. Göğüs, A. Özdemir, F. Sayıll, M. Altıntaş, A. ve Altıntaş, G. (2015). Fındık yetiştiren üreticilerin bitkisel ürün sigortası uygulamalarına yönelik yaklaşımı: Ordu ve Trabzon illeri örneği. Tarım Ekonomisi Dergisi, 21, 27-38.

İpekcioğlu, Ş., Işgın, T., Monis, T., Saner, G. ve Bilgiç, A. (2010). Güneydoğu Anadolu Bölgesinde devlet destekli bitkisel ürün sigortası yaptırma istekliliğinin belirlenmesi. Türkiye IX. Tarım Ekonomisi Kongresi, 22-24 Eylül, Şanlıurfa.

İşbeceren, V. (2018). Tekirdă̆ ili Süleymanpaşa ilçesi ziraat odasına üye çiftçilerin tarim sigortasina olan eğilimleri üzerine bir araştırma. (Y. Lisans Tezi). Tekirdağ Namık Kemal Üniversitesi Fen Bilimleri Enstitüsü, Tokat. 
Kabaoğlu, H. ve Birinci, A. (2019). Fındık üreticilerinin tarım sigortasına olan yaklaşımları ve geleceğe yönelik tutumlarının belirlenmesi: Düzce ili örneği. Journal of the Institute of Science and Technology, 9(3), 1719-1728.

Karakayacı, Ö. ve Dinçer, İ.(2018), Social networks and innovation in industrial clusters: A study in case of Turkish Industrial Clusters. MEGARON, 13(3), 374-394

Karamürsel, D., Emre, M., Öztürk, F.P., Sarısu, H.C., Karamürsel, Ö.F., Emre, R.A., Öztürk, G. ve Altıntaş, A. (2014). Isparta ilinde üreticilerin bitkisel ürün sigortası uygulamalarına yaklaşımı. XI. Ulusal Tarım Ekonomisi Kongresi, 3-5 Eylül, Samsun.

Kunreuther, H. (2015). The role of insurance in reducing losses from extreme events: The need for public-private partnerships. The Geneva Papers on Risk and InsuranceIssues and Practice, 40(4), 741 - 762

Nalinci S. (2018). Amasya ilindeki üreticilerin riske karşı tutumları ve tarım sigortası karar sürecinde etkili olan faktörlerin analizi. (Doktora Tezi). Gaziosmanpaşa Üniversitesi Fen Bilimleri Enstitüsü, Tokat.

OECD (2015), Analysing policies to improve agricultural productivity growth, sustainably: Draft Framework. May, 01.09.2019 tarihinde www.oecd.org/tad/agricultural-policies/Analysing-policiesimprove-agricultural-productivity-growth-sustainably-may2015.pdf. adresinden erişildi.

OECD (2016), Workshop on innovations in food and agriculture system: Policies to foster productive and sustainable solutions, 25-26 February 2016: Summary Report. 17.08.2019 tarihinde www.oecd.org/tad/events/workshop-innovations-food-agriculturefebruary-2016.htm. adresinden erişildi.

OECD ve Eurostat (2005), Oslo Manual: Guidelines for Collecting and Interpreting Innovation Data. 3.bs., 19.08.2019 tarihinde http://epp.eurostat.ec.europa.eu/cache/ITY PUBLIC/OSLO/EN/OSL O-EN.PDF adresinden erişildi.

Pezikoğlu, P. (2012), Bursa İlinde Bitkisel Ürün Sigortası Uygulamalarına Yönelik Çiftçi Yaklaşımı. 10. Ulusal Tarım Ekonomisi Kongresi, Konya

Schumpeter Joseph A.(1961). The theory of economic development: An inquiry into profits, capital, credit, interest, and the business cycle. Çev. Redvers Opie, USA, New York, Oxford University Press, s.66. 
Sungur, O, Koç, R. ve Dulupçu, M . (2014). Antalya'da tarım ve tarımla ilişkili firmalarin inovasyon ve yerel aktörlerle işbirliği faaliyetlerinin analizi. Tarım Ekonomisi Dergisi, 20(1-2), 1-15.

TARSIM Faaliyet Raporu (2019). 07.09.2019 tarihinde https://web.tarsim.gov.tr/havuz/faaliyetRaporu/2019/index.html adresinden erişildi.

Tümer, E.G.,(2011), Bitkisel ürün sigortası yaptırma isteğinin belirlenmesi: Tokat ili örneği. Atatürk Üniversitesi Ziraat Fakültesi Dergisi, 42(2), 153-157.

Van A. ve Macedo-Soares, D.(2016). International alliance portfolios and innovation: A proposal for an analytical model based on bibliographic and bibliometric research. Journal of Global Business and Technology, 12(1), 1-22.

World Bank (2006). Enhancing agricultural innovation: How to go beyond the strengthening of research systems. The World Bank,. Washington DC.

Yavuz, G. ve Tatlıdil, H . (2011). Üreticilerin tarım sigortası yaptırma kararlarında etkili olan faktörler: polatlı ilçesi örneği. Ziraat Mühendisliği , $357,34-41$.

Yazgı, F. ve Olhan, E. (2018). Türkiye tarım sigortası sisteminde görülen sorunlar ve alternatif model arayışı. Adnan Menderes Üniversitesi Ziraat Fakültesi Dergisi, 15(1) , 39-45.

\section{Kaynakça Bilgisi / Citation Information}

Kahramanoğlu, A. (2021). Tarım sigortaları kapsamında tarım üreticilerinin yenilikçilik tutumları. OPUS-Uluslararası Toplum Araştırmaları Dergisi, 18(Yönetim ve Organizasyon Özel Sayısı), 1643-1661. DOI: 10.26466/opus.907938 